\title{
Determination of Stature from Hand Length and Hand Breadth-An Anthropometric Study
}

\author{
Ashinie.C ${ }^{1}$, M.S.Thenmozhi ${ }^{2}$ and S. Sangeetha ${ }^{3}$ \\ ${ }^{1}$ Saveetha Dental College Saveetha Institute of Medical and \\ Technical science, Saveetha University, Chennai - 600077, India \\ ${ }^{2}$ Head of the department Department of anatomy Saveetha \\ Dental College, Saveetha Institute of Medical and Technical \\ Sciences, Saveetha University, Chennai - 600077, India \\ ${ }^{3}$ Lecturer Department of anatomy Saveetha Dental College, \\ Saveetha Institute of Medical and Technical Sciences, \\ Saveetha University, Chennai - 600077, India
}

\section{ABSTRACT}

Stature is a measure of natural height of a person. Stature determination is important in order to monitor the growth and health of a person. Measurement of height and weight is very important in examining the child's health. But when it comes to a person with disabilities or with any physical anomalies it becomes difficult to measure the exact stature of a person. Archaeologists who study the human past using remains find it is very difficult to determine the stature accurately. The aim of the study is to determine the stature from hand length and hand breadth. A group of 100 individuals were selected 50 males and 50 females who were healthy and without any deformities. Their height, left and right hand length (from wrist to tip of middle finger), left and right hand breadth (maximum breadth) were measured. The mean height, hand length and hand breadth were calculated and a regression equation was made and the correlation between hand length,and breadth with height was analysed. The regression equation was made based on the height, hand length and hand breadth. There was no significant difference between right hand dimension and left hand dimension. So the correlation was made for right hand dimensions and stature. Regression formula was used to determine the stature from hand length and breadth. The study concluded that hand dimensions can be used to determine the stature.

KEY WORDS: STATURE; HAND LENGTH; HAND BREADTH.

\section{INTRODUCTION}

Identification is the most important characteristic of a study. Identification plays an important role in knowing more about a particular object or a person. Identification

\section{ARTICLE INFORMATION}

*Corresponding Author: sangeethas.sdc@saveetha.com Received 28th July 2020 Accepted after revision 24th Sep 2020 Print ISSN: 0974-6455 Online ISSN: 2321-4007 CODEN: BBRCBA

Thomson Reuters ISI Web of Science Clarivate Analytics USA and Crossref Indexed Journal

\section{Clarivate
Analytics}

NAAS Journal Score 2020 (4.31) SJIF: 2020 (7.728)

A Society of Science and Nature Publication,

Bhopal India 2020. All rights reserved.

Online Contents Available at: http//www.bbrc.in/

Doi: http://dx.doi.org/10.21786/bbrc/13.8/151 of body parts can help the people of the forensic department in identifying the unknown bodies during accidents or natural calamities (Choudhary, Lakshman and Thenmozhi, 2019). Paramount importance to forensic experts and anthropologists is the estimation of stature (Subashri and Thenmozhi, 2016). Comparing other parameters, estimation of stature is an important parameter in medico legal examinations and anthropological studies (Vijeta and Kapoor, 2012). Determination of stature from dismembered body parts can play a vital role for identification of a person and it is considered as one of the main parameters of personal identification (Varu et al., 2015). 
Among the various parameters of identification, individual's stature is an inherent characteristic, the estimate of which is considered to be important in those cases where only fragmentary or mutilated remains of an unknown person are recovered (Dikshit et al., 2005). The relationship of dimensions between the segments of the body and the whole body has been the focus of anthropologists, scientists, and anatomists for many years (Ibrahim et al., 2018). Body proportions and the dimensions of various body segments, including the long bones of the limbs and the bones of the foot and hand have been used to estimate stature in previous articles which have been the pioneer for determining stature from various dimensions of our body (Pungle and Code, no date). Due to strong influence of genetic and environmental factors on the height of the individual, homogeneity of the study population is vital in formulating the regression equations (Geetha and Swathi, 2015).

Regression equation is an equation formed to estimate the relationship between height (dependent variable) and hand dimensions (independent variable). Regression equation was formed to determine the stature from hand dimensions. Stature determination also differs with age, sex and race. Each race requires its own formula for stature estimation as variations that exist in one population cannot be entirely applicable to other populations (Krishna, Nivesh Krishna and Yuvaraj Babu, 2016). Many previous morphometric studies (Keerthana and Thenmozhi, 2016), (Choudhari and Thenmozhi, 2016), (Kannan and Thenmozhi, 2016) and studies in determining stature from different dimensions were done that led us to conduct a study to determine stature from hand length and hand breadth both in males and females using a regression formula.

\section{MATERIAL AND METHODS}

A cross-sectional descriptive study was carried out randomly on 100 right-handed normal healthy adults between the age group of 17 to 20 years. The research population included 50 males and 50 females as a study population. Four measurements of different hand dimensions (right hand length, right hand breadth, left hand length and left hand breadth) were taken from each participant. Participants those with poorly defined wrist creases, physical acquired or congenital deformities, injuries, fractures, amputations or history of surgical intervention of the hands were excluded from the study. The stature of the people was measured first. They were asked to stand on the base of the standard stadiometer with their heels separated.The individuals were made to stand straight such that their whole body lies on the same axis.

The headpiece was kept over the individual's head and then the total height of a person in their standing position was measured. The length and breadth of the hand were measured using a centimetre scale.The hand length was measured from the proximal crease of the wrist to the tip of the middle finger when the hand was held straight and stretched. The hand breadth was measured from the most remote points on the heads of the 1st and 5th metacarpal bones. The regression equation was formed and correlation was made to determine the stature from hand dimensions.

Figure 1: Represents the correlation between height and hand length in males. $\mathrm{X}$ axis represents the hand length of males and $\mathrm{Y}$ axis represents the height of males. The regression equation was found to be $\mathrm{y}=-0.12616 \mathrm{X}+$ 170.97594 which is a negative correlation.

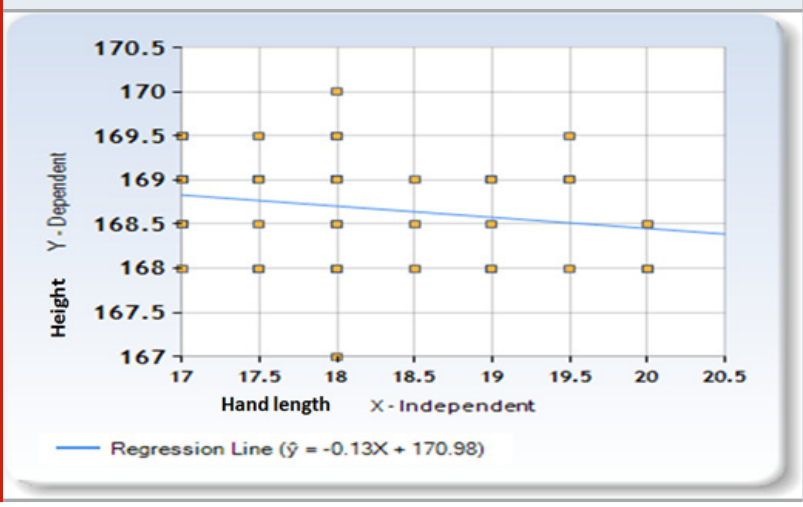

Figure 2: Represents the correlation between height and hand length in females. $\mathrm{X}$ axis represents the hand length of females and $\mathrm{Y}$ axis represents the height of females. The regression equation was found to be $\mathrm{y}=0.08297 \mathrm{X}+$ 157.1396, which is a positive correlation.

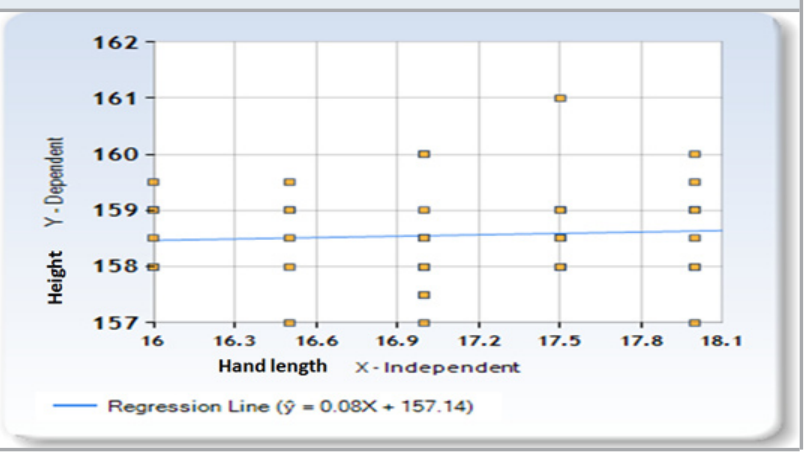

\section{RESULTS AND DISCUSSION}

The stature of each of the participants is measured and the mean stature of males is $168.69 \mathrm{~cm}$ and of females is $158.56 \mathrm{~cm}$. Both right and left hand dimensions of the participants were measured but there were no significant differences between right and left hand dimensions so only right hand dimensions were used to analyse the correlation between hand dimensions and stature. The mean hand length of males is $18.12 \mathrm{~cm}$ and of females is $17.12 \mathrm{~cm}$. The mean hand breadth of males is $8.69 \mathrm{~cm}$ and of females is $7.96 \mathrm{~cm}$. The correlation between hand length and breadth with stature was done using a regression equation. The regression equation of height on hand length for males is $\mathrm{y}=-0.12616 \mathrm{X}+$ 170.97594 (Figure 1) and for females is $\mathrm{y}=0.08297 \mathrm{X}+$ 157.1396 (Figure 2). The regression equation of height 
on hand breadth for males is $\mathrm{X}=0.22118 \mathrm{X}+166.76791$ (Figure 3) and for females is $\mathrm{x}=0.10985 \mathrm{X}+157.68561$ (Figure 4) to determine the stature from hand length and hand breadth.

Figure 3: Represents the correlation between height and hand breadth in males. $\mathrm{X}$ axis represents the hand length of males and $\mathrm{Y}$ axis represents the height of males. The regression equation was found to be $\mathrm{y}=0.22118 \mathrm{X}+$ 166.76791, which is a positive correlation.

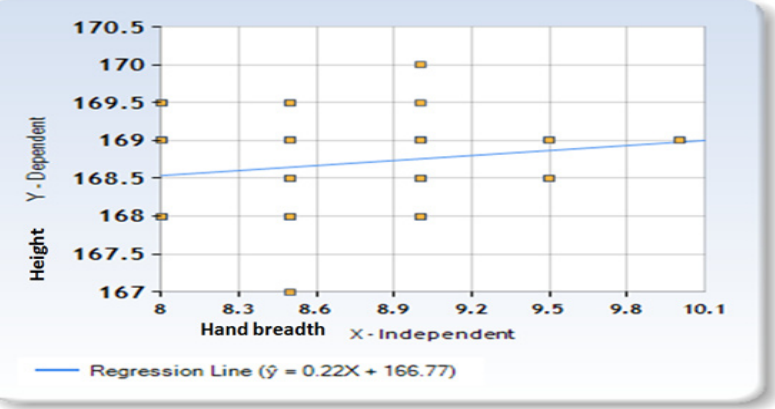

Figure 4: Represents the correlation between height and hand breadth in females. $\mathrm{X}$ axis represents the hand length of females and $\mathrm{Y}$ axis represents the height of females. The regression equation was found to be $\mathrm{y}=0.10985 \mathrm{X}+$ 157.68561, which is a positive correlation.

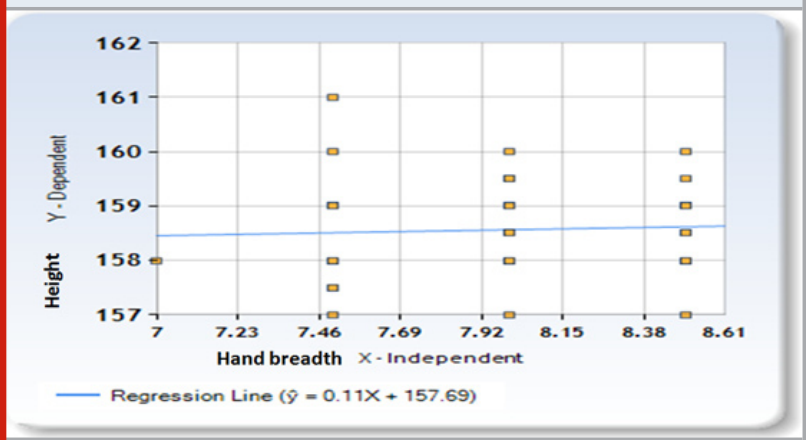

In the present study a regression equation was formed to determine the stature. Previous studies were done to determine stature from hand dimensions in specific populations like the Bengalee population where they concluded that hand dimensions can be used to determine stature. This study portrays the determination in a specific population(Pal et al., 2016). In the study done by Prithviraj Karak et al a regression formula was formed to determine stature from tibial length and a good correlation was found which was highly statistically significant(Anirban, Arindam and Prithviraj, 2013). Previous studies were also done to determine the stature from foot length which also showed a good correlation and was statistically significant(Jakhar, Pal and Paliwal, 2010). In previous studies done in kashmiri population a positive correlation was found between hand length and stature(Khan et al., 2017) but in present study a negative correlation was found between stature and hand length in males which was not significant.

Previous studies were also done on determining the stature from long bones and showed a positive correlation which is very helpful in medico legal investigation (Arora and Khan, 2018). The present study does not involve any bones instead stature was only determined by the morphological dimensions. Previous studies which calculated stature from hand dimensions showed hand length more correlated to the stature (Patel, Parekh and Patel, 2014) but in the present study hand length in males showed a negative correlation while hand breadth had positive correlation with stature in both males and females.

The main limitation of the study is that it is done only with 100 individuals . the study population is less and it included only students of a certain age group. In future extensive study on determining the stature from hand dimensions can be done for various age groups and can be analysed more accurately. More extensive studies with varied populations will help in the field of research and forensic in identification.

\section{CONCLUSION}

Various studies have been done to determine stature from various dimensions. The present study concludes that hand dimensions can be used to determine the stature with accuracy and it can be used in various fields for identification. This study shows a regression formula to determine the stature from hand length and hand breadth in both males and females but hand breadth showed more correlation to stature than hand length. This may vary according to the type of population included in the study. Further extensive studies with different populations may establish an accurate formula to determine stature from hand length and breadth.

\section{ACKNOWLEDGEMENTS}

The author would like to thank the study participants for their participation and kind cooperation throughout the study

Conflict of Interest: The author declared that there was no conflict of interest in the present study .

\section{REFERENCES}

Anirban, D., Arindam, B. and Prithviraj, K. (2013) 'Estimation of stature of Eastern Indians from measurements of tibial length', Anatomy \& physiology: current research, 3(115), pp. 2161-0940.

Arora, B. S. and Khan, M. W. (2018) 'Estimation of Stature from Femur Length-A Forensic Study', Journal of Advanced Medical and Dental Sciences Research. Journal of Advanced Medical and Dental Sciences Research (JAMDSR), 6(11), p. 23.

Choudhari, S. and Thenmozhi, M. S. (2016) 'Occurrence and Importance of Posterior Condylar Foramen', Research Journal of Pharmacy and Technology. A \& V Publications, 9(8), pp. 1083-1085.

Choudhary, A., Lakshman, G. and Thenmozhi, M. S. (2019) 'Estimation of stature using hand dimension', 
Drug Invention Today, 11(8).

Dikshit, P. C. et al. (2005) 'Estimation of stature from hand length', Journal of Indian Academy of Forensic Medicine. Indian Academy of Forensic Medicine, 27(4), pp. 219-221.

Geetha, G. N. and Swathi, S. A. A. (2015) 'Estimation of stature from hand and foot measurements in a rare tribe of Kerala state in India', Journal of clinical and diagnostic research: JCDR. JCDR Research \& Publications Private Limited, 9(10), p. HC01.

Ibrahim, M. A. et al. (2018) 'Estimation of stature from hand dimensions in North Saudi population, medicolegal view', The Saudi Journal of Forensic Medicine and Sciences. Medknow Publications and Media Pvt. Ltd., 1(1), p. 19.

Jakhar, J. K., Pal, V. and Paliwal, P. K. (2010) 'Estimation of height from measurements of foot length in Haryana region', Journal of Indian Academy of Forensic Medicine. Indian Academy of Forensic Medicine, 32(3), pp. 231-233.

Kannan, R. and Thenmozhi, M. S. (2016) 'Morphometric Study of Styloid Process and its Clinical Importance on Eagle's Syndrome', Research Journal of Pharmacy and Technology, p. 1137. doi: 10.5958/0974360x.2016.00216.x.

Keerthana, B. and Thenmozhi, M. S. (2016) 'Occurrence of foramen of huschke and its clinical significance', Research Journal of Pharmacy and Technology. A \& V Publications, 9(11), pp. 1835-1836.

Khan, M. A. et al. (2017) 'Determination of stature from measurements of hand length and hand breadth; an anthropometric study of Kashmiri population', Int J Anat Res, 5(2.3), pp. 3968-3975.

Krishna, R. N., Nivesh Krishna, R. and Yuvaraj Babu, K. (2016) 'Estimation of stature from physiognomic facial length and morphological facial length', Research Journal of Pharmacy and Technology, p. 2071. doi: 10.5958/0974-360x.2016.00423.6.

Pal, A. et al. (2016) 'Estimation of stature from hand dimensions in Bengalee population, West Bengal, India', Egyptian Journal of Forensic Sciences, 6(2), pp. 90-98.

Patel, R., Parekh, U. and Patel, P. (2014) 'A study of estimation of stature from hand length in Gujarat', NHL Journal of Medical Sciences, 3(2).

Pungle, A. S. and Code, Q. R. (no date) 'Estimation of stature from hand length and foot length in Nagpur region of Maharashtra State'.

Subashri, A. and Thenmozhi, M. S. (2016) 'Estimation of stature using hand length in South Indian Region', Janus; revue internationale de l'histoire des sciences, de la medecine, de la pharmacie, et de la technique, 40, pp. 52-54.

Varu, P. R. et al. (2015) 'Determination of stature from hand dimensions', Journal of molecular recognition: JMR, 1(3), pp. 104-107.

Vijeta, K. A. K. and Kapoor, A. K. (2012) 'Estimation of stature from hand length and hand breadth among population groups of Himachal Pradesh', Asian J. Science \&t Applied Technology (Accepted). 